\title{
MONITORING SIDE EFFECTS OF ANTIRETROVIRAL THERAPY IN PATIENTS WITH HUMAN IMMUNODEFICIENCY VIRUS/ACQUIRED IMMUNODEFICIENCY SYNDROME
}

\author{
SANTI PURNA SARI*, SITI RIZKY ISNAINI, ATIKA WAHYU PUSPITASARI
}

Clinical Pharmacy Laboratory, Faculty of Pharmacy, Universitas Indonesia, Depok 16424, Indonesia. Email: santisari@farmasi.ui.ac.id Received: 29 June 2018, Revised and Accepted: 28 September 2018 and 26 October 2018

\begin{abstract}
Objective: This study aimed to monitor the side effects of patients who received antiretroviral medications in a subdistrict of West Jakarta in 2017.

Methods: Descriptive research was performed using data collected prospectively from patients who met our inclusion criteria (total sampling). Primary data were obtained from interviews, and secondary data were obtained from medical and prescription records. The Naranjo algorithm was used to classify side effects.
\end{abstract}

Results: The side effects experienced by patients in this study fell into probable (45.45\%) and possible (36.36\%) categories. However, age (p=0.379), gender $(\mathrm{p}=1)$, and length of treatment $(\mathrm{p}=0.07)$ did not significantly affect the occurrence of side effects.

Conclusion: Monitoring the side effects of antiretroviral medicine is necessary to prevent serious and rare side effects. The occurrence of side effects, whether they have an established causal relationship or not, could be prevented by appropriate monitoring.

Keywords: Antiretroviral, Correlation, Naranjo algorithm, Side effect monitoring

(C) 2018 The Authors. Published by Innovare Academic Sciences Pvt Ltd. This is an open access article under the CC BY license (http://creativecommons. org/licenses/by/4. 0/) DOI: http://dx.doi.org/10.22159/ijap.2018.v10s1.71

\section{INTRODUCTION}

Acquired immunodeficiency syndrome (AIDS) is caused by infection with the human immunodeficiency virus (HIV). This retrovirus infects the body and compromises the function of the immune system. As the infection progresses, the body's immune system is weakened, and the sufferer becomes more prone to infection [1]. The World Health Organization reported that there were 36.7 million people worldwide with HIV in 2015 and that 2.1 million of these had been newly detected that year [2]. In Indonesia, based on a report from information system HIV/AIDS, there were 7146 people with HIV in 2016, of which 4333 were male and 2813 were female. The highest risk for HIV transmission in Indonesia between 2010 and 2016 was from sexual intercourse (67,734 people) [3].

To date, no medications have been developed that can kill HIV, but highly active antiretroviral therapy, which involves combining drugs from several classes, can be used to inhibit HIV replication and slow disease progression [4]. Antiretrovirals help to decrease the risk of HIV transmission, limit severe opportunistic infection, improve quality of life, and decrease the total viral count in the blood to undetectable levels. Four antiretroviral classes, grouped by their mechanism of action, are combined to achieve these therapeutic aims in double or triple therapy [5]. The first group is the nucleoside reverse transcriptase inhibitors, which comprises zidovudine, tenofovir, stavudine, abacavir, and lamivudine. The second group comprises the non-nucleoside reverse transcriptase inhibitors such as nevirapine and efavirenz. The third group comprises lopinavir, a protease inhibitor, and the fourth group comprises raltegravir, an integrase strand transfer inhibitor [6].

Despite the efficacy of antiretroviral therapy, around $25 \%$ of the sufferers stop therapy in the first 8 months because of treatment failure, noncompliance, and side effects [7]. The latter can be affected by gender, age, and the duration of drug use. Females tend to suffer from side effects due to the effects of hormonal changes during the menstrual cycle on drug metabolism [8]. Based on research in India, the greatest frequency of side effects occurred in the patients aged $41-50$ years (68.8\%), followed by those aged 31-40 years (53.08\%) [9]. The possibility of side effects because of drug toxicity increases the longer patients who are treated with a given medication [10]. Drug side effects, including serious, rare, and previously unknown events, can be prevented if proper monitoring is done by medical professionals. The Indonesia Ministry of Health recommends monitoring for the side effect to improve patient compliance, using the Naranjo algorithm to assess this outcome quantitatively [11].

The Kembangan Subdistrict Health Centers, West Jakarta, are public health facilities that provide antiretroviral therapy. However, we have no reports about the side effect of the antiretroviral drug usage in these facilities. A pharmacy standardization service is available in this area [11], so we considered that their data could be used to investigate side effect rates from antiretroviral drugs in West Jakarta.

\section{METHODS}

We used an analytic descriptive research design to investigate the monitoring of side effects in patients receiving antiretroviral medications in a subdistrict of West Jakarta between March and May, inclusive, 2017. First, descriptive data were collected, before those data were analyzed to identify relationships between side effects and factors such as age, gender, and duration of therapy. The data collection was done prospectively [12]. We included patients with HIV/AIDS, who were registered in facilities in Kembangan, who consented to become research subjects, and who had received highly active antiretroviral therapy for at least 7 days. Patients were excluded if they had a comorbid or other health disorder, a history of side effects because of antiretroviral therapy, and a current opportunistic infection. Data were collected from primary interview data and secondary data from medical and prescription records. Analyses were then done using IBM SPSS, version 23 for Mac. The sample collection technique was total sampling.

\section{RESULTS}

In total, we identified 25 patients who received antiretroviral therapy in the participating facilities in West Jakarta during the study period; 
of these, 23 met the inclusion criteria, and two were excluded because they did not consent to participate. One of the patients died during the study so was excluded because the follow-up was not possible. The final cohort comprised 22 patients, and their characteristics are summarized in Table 1.

Details regarding their experience of side effects are summarized in Tables 2 and 3. Next, we analyzed the relationship between side effects and age, gender, or duration of therapy affected drug usage (Tables 4-6). As shown in Table 4, there was no relationship between age and side effects on antiretroviral drug usage ( $\mathrm{p}=0.379$; Chi-square test). Table 5 shows that there was also no relationship between gender and side effects on antiretroviral drug usage ( $\mathrm{p}=1.00$, Chi-square test). Similarly, there was no significant relationship between the drug usage duration and side effects on retroviral drug usage, though this did approach the significance threshold of 0.05 ( $p=0.070$; Mann-Whitney U-test).

Table 1: Patient characteristics

\begin{tabular}{ll}
\hline Category & Number $\mathbf{n = 2 2}(\mathbf{\%})$ \\
\hline Age & $7(31.82)$ \\
Late adolescent & $9(40.91)$ \\
Early adult & $6(27.27)$ \\
Late adult & \\
Gender & $9(40.91)$ \\
Female & $13(59.09)$ \\
Male & \\
Drug usage data (combination therapy) & $15(68.18)$ \\
Tenofovir+lamivudine+efavirenz & $2(9.09)$ \\
Tenofovir+lamivudine+nevirapine & $3(13.63)$ \\
Zidovudine+lamivudine+nevirapine & $1(4.54)$ \\
Tenofovir+efavirenz & $1(4.54)$ \\
Lopinavir+ritonavir & \\
Drug usage & $8(36.36)$ \\
4 weeks-5 months & $8(36.36)$ \\
$>5-12$ months & $6(27.27)$ \\
$>1$ year & \\
\hline
\end{tabular}

Table 2: The classification of side effects by Naranjo algorithm result

\begin{tabular}{ll}
\hline Category & Total patients $\mathbf{n = 2 2 ( \% )}$ \\
\hline Probable & $10(45.45)$ \\
Possible & $8(36.36)$ \\
\hline
\end{tabular}

\section{DISCUSSION}

\section{Patient characteristic}

Based on a report of the Centers for Disease Control and Prevention (CDC), the two age ranges with the highest HIV infection rates in 2015 in the United States were 20-24 years $(\mathrm{n}=7084)$ and $25-29$ years $(n=7510)$. These were followed by the age of 35-39 years, indicating that late adolescence to middle-age has the highest HIV infection rates [13]. Our results were consistent with these data reported by the CDC. Similarly, we showed that more males (59.09\%) than females $(40.91 \%)$ used antiretroviral drugs, which was also consistent with the finding by the CDC that males were more prone to infection. This may be related to males being more likely to engage in higher risk behaviors, including homosexual and heterosexual intercourse and non-sterile syringe use [13].

In this study, tenofovir, lamivudine, and efavirenz were the most frequently used combination $(\mathrm{n}=15)$. This is a first-line option in the Indonesia Ministry of Health guidance. The next most frequent combination was tenofovir, lamivudine, and nevirapine $(n=3)$, which were given to patients who experienced intense side effects with efavirenz. This is an appropriate alternative regimen in Indonesia [5]. Another three patients used zidovudine, lamivudine, and nevirapine. Beyond these, one patient used dual therapy with tenofovir and efavirenz, but the reason for omitting lamivudine was not specified, and one other patient used second-line options (lopinavir and ritonavir). The reason for using these latter agents was drug discontinuation due to intense side effects experienced with the first-line combination of tenofovir, zidovudine, and efavirenz.

In total, eight patients in this study had used antiretroviral drugs for 4 weeks -5 months, another eight had used them for 6-12 months, and six had used them for $>1$ year (the usage range was 1 month-10 year). Antiretrovirals are to be used for life, so the duration of usage in this research referred to the time of the drug usage since the $1^{\text {st }}$ time the patient received the drug to the last month of side effect monitoring by the research. Thus, unless stated otherwise, patients would be still using a given antiretroviral after the researcher stopped.

\section{Side effects}

The scores of the Naranjo algorithm indicated that most side effects probably happened because of the antiretroviral drug use. However, four of the 22 participants did not suffer from side effects during the monitoring period (range, 1-12 months; Table 2). The side effects experienced by patients are summarized in Table 3 based on the

Table 3: The Incidence of side effect by drug combination

\begin{tabular}{llll}
\hline Antiretroviral combination & Side Effect & Incidence & Total \\
\hline Lamivudine+tenofovir+efavirenz & Nausea & 6 & 28 \\
& Vomit & 5 & 3 \\
& Skin rash & 6 & 1 \\
& Headache & 7 & \\
Lamivudine+tenofovir+nevirapine & Central nervous system disturbance & 1 & \\
& Nausea & 1 & \\
Lamivudine+zidovudine+nevirapine & Vomit & 1 & \\
& Skin rash & Headache & 2 \\
Tenofovir+efavirenz & Nausea & 2 & \\
Lopinavir+ritonavir & Skin rash & 1 & \\
& Headache & 1 & 2 \\
\hline
\end{tabular}


Table 4: Relationship between age and side effects on drug usage

\begin{tabular}{llll}
\hline Category & Total patients $(\mathbf{n = 2 2})$ & Side effects & Percentage (\%) \\
\hline Age & & & \\
Early adolescent $(12-16$ years $)$ & 0 & 0 & 0 \\
Late adolescent $(>16-25$ years $)$ & 7 & 5 & 71.4 \\
Early adult $(>25-35$ years $)$ & 9 & 6 & 77.8 \\
Late adult $(>35-45$ years $)$ & 6 & 6 & 100 \\
\hline
\end{tabular}

Table 5: Relationship between gender and side effects on drug usage

\begin{tabular}{lllll}
\hline Category & Total patients $(\mathbf{n}=\mathbf{2 2})$ & Side effect & Percentage (\%) & p \\
\hline Age & & & & \\
Female & 7 & 6 & 85.7 & 1.000 \\
Male & 15 & 12 & 80 & \\
\hline
\end{tabular}

Table 6: Relationship between drug usage duration and side effects on drug usage

\begin{tabular}{llll}
\hline Category & Total patients $(\mathbf{n}=\mathbf{2 2})$ & Side effect & Percentage (\%) \\
\hline Usage duration & & & \\
$>3$ weeks-5 months & 8 & 6 & 75 \\
$>5-12$ months & 8 & 6 & 75 \\
$>1$ year & 6 & 6 & 100 \\
\hline
\end{tabular}

antiretroviral combination. As shown, nausea, vomiting, skin rash, and headache were universal side effects, and patients often suffered all of these (e.g., interview revealed that a patient could suffer nausea, followed by vomiting and headache). Nausea and vomiting can be treated pharmacologically (e.g., antiemetics) and non-pharmacologically (e.g., counseling about nutrition), making their identification relevant. It seemed that most common side effects were only experienced early during therapy.

The most common side effect was central nervous system disturbance, and this included nightmares, hallucinations, "float-like" flying sensation, and conscious dreams. These side effects were probably due to efavirenz [14] and occurred in seven patients receiving lamivudine, tenofovir, and efavirenz. Our findings are supported by the research of Jain et al. in India [15]. They showed that the most commonly used therapeutic combination was lamivudine, tenofovir, and efavirenz ( 83 of 100 patients), but that 81 experienced side effects due to efavirenz [15]. Although the side effects of efavirenz commonly disappeared after 6-10 weeks, they could persist long-term in some patients [16].

The most serious side effect of all antiretrovirals is hepatotoxicity. In addition, nucleoside reverse transcriptase inhibitors may cause lactic acidosis, kidney failure, and anemia, while protease inhibitors may cause the Stevens-Johnson syndrome. Lactic acidosis could happen because of mitochondrial toxicity, with gamma polymerase DNA being inhibited by the nucleoside reverse transcriptase inhibitors [16], but there was no evidence of this side effect in our cohort (Table 3). However, the medical records only covered laboratory results for serum glutamic oxaloacetic transaminase, glutamic pyruvic transaminase, and urea, as well as the creatinine clearance. We were still able to conclude that the hepatic and kidney functions of all patients were normal.

\section{Relationship between age and side effects}

There was no relation between age and side effects in terms of antiretroviral drug usage (Table $4, \mathrm{p}=0.379$ ). Malalur et al. found that adults had a higher prevalence of side effects because of pharmacokinetic factors such as absorption, distribution, metabolism, and elimination [17]. In adults, gastric acid levels could be increased and stomach clearance could be delayed. Moreover, decreased efficiency of the digestive tract could lead to a decrease in the total amount of drug absorbed, and a disturbed water content of the body could increase the relative concentration of water-soluble drugs in the plasma. Hepatic and kidney function also decrease as we age, so impaired metabolism and excretion could also be factors [18-20]. Similar to our result, however, other research has shown that age did not influence side effect rates. The potential for side effects to increase with age could, therefore, be caused by unsuitable dosages and routes of administration for the patient's age; however, those factors are accounted for drug Category A and can be prevented [21]. The lack of a relationship between age and side effects in this research could be caused by the small sample size.

\section{Relationship between gender and side effects}

As with age, there was no relationship between gender and side effects in terms of antiretroviral drug use in our cohort (Table 5, $\mathrm{p}=1.00$ ). Other research has indicated that more males than females experience side effects when taking antiretroviral drugs. Indeed, it has been stated that the mean difference in weight and body mass index between males and females could account for different prevalence rates of side effects [8]. Furthermore, Floridia et al. reported that differences in side effect frequency could be caused by differences in hormonal factors, pharmacokinetic factors, compliance, and acceptance of side effects between the sexes [22,23]. Our failure to show a difference was probably a consequence of the small sample size. Further study is needed to clarify the relationship between gender and side effects.

Relationship between the duration of drug usage and side effects Finally, there was no significant relationship between the duration of drug usage and side effects on the use of antiretroviral drugs (Table 6), though this did approach the 2-tailed significance threshold of 0.05 (i.e., $\mathrm{p}=0.070$ ). Of the eight patients who had taken antiretroviral drugs for 4 weeks-5 months, a total of six (75\%) patients experienced side effects. Among the eight patients who had taken antiretrovirals for 6-12 months, another six (75\%) patients experienced side effects. However, of the six patients who had taken antiretrovirals for $>1$ year, all experienced side effects. Interviewing the patients revealed that the most intense side effects happened early during therapy (typically within the first 6 months), possible because of intolerance while the body became used to the drug. Careful monitoring for drug side effects during this early period could prevent drug discontinuation in some patients [24]. By contrast, monitoring in the long-term is important to identify toxicity and potentially serious side effects, such as kidney failure, bone marrow suppression, and anemia [10]. 


\section{CONCLUSION}

In West Jakarta in 2017, the most common first-line antiretroviral combination was lamivudine, tenofovir, and efavirenz (68.18\%), and there were 28 reports of side effects with antiretroviral usage, typically due to this combination. However, there was no significant relationship between age, gender, or duration of drug usage and side effects.

\section{CONFLICTS OF INTEREST}

All authors have none to declare

\section{REFERENCES}

1. World Health Organization. HIV/AIDS; 2016. Available from: http:// www.who.int/features/qa/71/en/. [Last accessed on 2017 Jan 30].

2. World Health Organization. Global Summary of the AIDS Epidemic; 2016. Available from: http://www.who.int/hiv/data/epi_core_2016. png?ua $=1$. [Last accessed on 2017 Jan 30].

3. Ministry of Health. HIV/AIDS Progress Report Quarter I); 2016. Available from: http://www.spiritia. or.id/Stats/stat2016.pdf. [Last accessed on 2017 Jan 30].

4. World Health Organization. Consolidated Guidelines on the use of Antiretroviral Drugs for Treating and Preventing HIV Infection: Recommendations for a Public Health Approach. World Health Organization (Second). Geneva: WHO Press; 2016.

5. Ministry of Health. Antiretroviral Treatment Guidelines. In: Regulation of the Minister of Health of the Republic of Indonesia No. 87 of 2014. Jakarta: Ministry of Health of the Republic of Indonesia; 2014. p. 1-121.

6. Wells BG, DiPiro JT, Schwinghammer TL, Dipiro CV. Pharmacotherapy Handbook. $9^{\text {th }}$ ed. New York: Mc Graw Hill Education; 2015.

7. Montessori V, Press N, Harris M, Akagi L, Montaner JS. Adverse effects of antiretroviral therapy for HIV infection. CMAJ 2004;170:229-38.

8. Ofotokun I, Pomeroy C. Sex differences in adverse reactions to antiretroviral drugs. Top HIV Med 2003;11:55-9.

9. Srikanth BA, Babu SC, Yadav HN, Jain SK. Incidence of adverse drug reactions in human immune deficiency virus-positive patients using highly active antiretroviral therapy. J Adv Pharm Technol Res 2012;3:62-7.

10. Eluwa GI, Badru T, Agu KA, Akpoigbe KJ, Chabikuli O, Hamelmann C, et al. Adverse drug reactions to antiretroviral therapy (ARVs): Incidence, type and risk factors in Nigeria. BMC Clin Pharmacol 2012;12:7.
11. Agency for Drug and Food Control of the Republic of Indonesia. Guidelines for Side Effects of Drugs Monitoring (MESO) for Health Personnel. Jakarta: Badan POM RI; 2012.

12. Notoatmodjo S. Health Research Methodology. Jakarta: Rineka Cipta; 2010.

13. Centers for Disease Control and Prevention. HIV Surveillance Report; 2013. Published February 2015. Available from: http://www.cdc.gov/ hiv/library/reports/surveillance. [Last accessed on 2017 Jan 30].

14. Hawkins T. Understanding and managing the adverse effects of antiretroviral therapy. Antiviral Res 2010;85:201-9.

15. Jain A, Lihite RJ, Lahkar M, Baruah SK. A study on adverse drug reactions to first-line antiretroviral therapy in HIV infected patients at a tertiary care hospital in Northeast India. HIV AIDS Rev 2016;15:131-5.

16. Khan K, Khan AH, Sulaiman SA, Soo CT, Ahsan R. Adverse effect of highly active anti-retroviral therapy (HAART) In HIV/AIDS patients. Indian J Pharm Pract 2014;7:6-11.

17. Malalur C, Shenoy S, Varma M, Kamath A, Manohar H, Saravu K. Evaluation of adverse drug reaction profile of antiretrovirals in HIVpositive patients in a tertiary care hospital. Natl J Physiol Pharm Pharmacol 2016;6:488-93.

18. Corsonello A, Pedone C, Incalzi RA. Age-Related pharmacokinetic and pharmacodynamic changes and related risk of adverse drug reactions. Curr Med Chem 2010;17:571-84

19. Adiga SM, Adiga US. Effect of antiretroviral treatment regimens on liver enzymes in human immunodeficiency virus patients. Asian J Pharm Clin Res 2018;11:95-9.

20. Bhatnagar S, Sharma H, Sharma VK. Study of adverse effects of anti retroviral therapy in HIV naïve patients and their association with CD4 cell count. Asian J Pharm Clin Res 2013;6:122-4.

21. Mehta U, Durrheim DN, Blockman M, Kredo T, Gounden R, Barnes KI. Adverse drug reactions in adult medical inpatients in a South African hospital serving a community with a high HIV/AIDS prevalence: Prospective observational study. Br J Clin Pharmacol 2008;65:396-406.

22. Floridia M, Giuliano M, Palmisano L, Vella S. gender differences in the treatment of HIV infection. Pharmacol Res 2008;58:173-82.

23. Sandeep BV, Raghunandan M, Mohammad A, Suresh BS. Factors influencing the substitution of ART in HIV/AIDS patients on first line highly active antiretroviral therapy. Asian J Pharm Clin Res 2014;7:117-20.

24. Duval X, Journot V, Leport C, Chêne G, Dupon M, Cuzin L, et al. Incidence of and risk factors for adverse drug reactions in a prospective cohort of HIV-infected adults initiating protease inhibitor-containing therapy. Clin Infect Dis 2004;39:248-55. 